\title{
IAMJ
}

INTERNATIONAL

AYURVEDIC

MEDICAL JOURNAL

ISSN: 2320-5091

Impact Factor: 6.719

\section{YOG AND INDIAN DIETETICS IN MANAGEMENT OF MILD COGNITIVE IMPAIRMENT (MCI): A COMPLIMENTARY REMEDIAL REVIEW}

\author{
$\underline{\text { Supriya Joshi }}^{1}, \underline{\text { Saloni Jadhav }}^{2}$ \\ ${ }^{1,2}$ Assistant Professor, Department of Ayurved, Tilak Maharashtra Vidyapeeth, Mukund Nagar, \\ Pune -37, Maharashtra, India
}

Corresponding Author: svjshankhnaad@gmail.com

https://doi.org/10.46607/iamj2509122021

(Published Online: December 2021)

Open Access

(C) International Ayurvedic Medical Journal, India

Article Received: 25/11//2021 - Peer Reviewed: 10/12/2021 - Accepted for Publication 11/12/2021

\section{Check for updates}

\section{ABSTRACT}

Background: Yog and nutrition have been placed in the limelight since an extensive era for the management of all-cause cognitive impairment. As the global population is ageing rapidly as exhibited that over two billion individuals will be crossing 60 years by 2050 , the rate of cognitive decline or impairment will also be a challenge to the healthcare providers. Methodology: The main aim of the present review is to examine the promising benefits of $Y o g$ and ancient Indian nutrition science in the overall management of early and mild cognitive impairment and dementia. Many ancient classical Indian texts such as Gherand Samhita, Patanjali Yoga sutra, Charak Samhita, Sushruta Samhita etc., have been extensively referred for the current scoping review.

Keywords: Yog, Indian dietetics, Mild cognitive decline, dementia.

\section{INTRODUCTION}

The world is ageing rapidly. This can be confidently mentioned by the odds that over two billion individuals will be crossing age 60 by $2050 .{ }^{[1]}$ With the advancing age, the risks of morbidities and comorbidities also rise. The ageing population often experiences a gradual decline in multiple organ func- tion; whereby age-related cognitive decline of various degrees is also a common finding. Mild cognitive impairment (MCI) has been noted to range between $10-20 \%$ in samples of population-based studies in older adults. Individuals with MCI have a 2.5- fold high risk for developing all-cause dementia, and MCI 
is often a precursor to Alzheimer's disease (AD) ${ }^{[2]} \mathrm{MCI}$ is normally considered as the borderline between age-associated cognitive changes and early dementia. ${ }^{[3]} \mathrm{MCI}$ remains an active area of research as numerous randomized controlled trials are being conducted to develop effective treatments. ${ }^{[4]}$ In India and its subcontinents, since aeons back the ancient sciences of yoga and nutrition have been practised widely for their colossal benefits on the human body, mind and soul. The same yogic science has demonstrated massive openings for maintaining and enhancing cognitive and mental wellness via different means such as asanas, pranayama, trataka etc. Similarly, ancient Indian dietetics as provided by Ayurveda also exhibits excellent supporting nutritional remedies to retain and enhance cognitive capacity as well as its functioning. The current review mainly aims at profoundly reviewing these original classical texts such as Patanjali Yogasutra, Gheranda Samhita, Hatayoga Pradipika etc. for yogic effect on cognition and olden novels like Bhojankutuhalam, Khsemakutuhalam, Charak Samhita, Sushrut Samhita, Bhavaprakasha etc. for authentic and dependable knowledge. We are positive that this review will certainly help the entire global population to take appropriate steps in order to retard or cease cognitive disturbances and MCI.

\section{Yogic Science and Cognition}

Memory remains at the core of human's existence. It is an information processing system and is a powerful tool for mankind's survival. Obviously, there is a strong need to preserve this ability and enhance its power. Cognition is the ultimate function of the brain. Executive cognition like decision making, planning and sequencing of responses, problem-solving, multitasking declines with advancing age.[5]. There are structural and functional changes in the brain that correlate with the everyday ability to function. There is growing evidence that a healthy lifestyle may decrease the speed of declining cognitive behaviour. A healthy lifestyle includes physical activity, mental stimulation and proper nutrition. Trataka, a type of yoga practice is considered to improve cognitive function. Trataka practice involves various steps like preparatory eye exercises, focusing, defocusing, chanting, and silence during relaxation. Each component or all of them together could have been responsible for the improvement in cognitive functions. Out of eight components of Ashtang Yoga Yama, Niayama, Asana, Pranayama, Pratyahara, Dharana, Dhyana and Samadhi the first four are related to the body (Sharira), the next three are related to mind (Manas) and the last one is for Atma (spirit). Focusing practised in Dharana improves concentrative attention ( "Desha-bandhaschittasya dharanam" Patanjali Yoga Sutras, Chapter III, Verse 1). As in Trataka, the focus is restricted to an object like a candle flame or one's own breathing. This is practised in dharana. In dhyana focus does not need any object. When dharana becomes effortless it becomes dhyana and requires no object. Also, vigilance and attention become needless. This phase of meditation leads to a calm yet alert mind. Dhyana is associated with reduced sympathetic activity and increased vagal tone.[7] The defocussed phase of Trataka could be similar to the benefits of dhyana phase of meditation. Multiple studies show that meditation may affect multiple pathways that could play a role in brain ageing and mental fitness. [8] Also focusing and defocusing alternatively improves mental alertness. Meditation processes are linked to gamma-aminobutyric acid (GABA) ergic cortical inhibition; a mechanism implicated in improved cognitive performance and enhanced emotional regulation. (9) Further, meditation may potentially strengthen neuronal circuits and enhance cognitive reserve capacity. Brain regions associated with attention, interception, and sensory processing are thicker in meditation practitioners including the PFC and right anterior insula.[10] Advanced meditators have higher melatonin levels (that blocks the build-up of beta-amyloid plaque, a hallmark feature of Alzheimer's disease) (11) than nonmeditators. The research also suggests that dhyana is associated with reduced sympathetic activity and increased vagal tone, whereas dharana does indeed improve performance in an attention task. ${ }^{6}$ Yogic breathing exercises known as Pranayam and its types; a form of meditation are practised for well- 
being, self-awareness. Pranayam is also practised to improve lung and cognitive capacities, reduce blood pressure, anxiety and other psychosomatic responses. Pranayam involves three components Puraka, Kumbhaka, and Rechaka. Previous studies show significant improvement in cognitive functions with the practice of different yoga practices. (27) Considering postures, breathing, and meditative exercises the three components of Hatha Yoga; yoga therapy enables the practitioner to move slowly and safely relaxing the body. Concentrating on movements of the body and breathing fully yoga develops the awareness of sensation in the body and thoughts in the mind.

Table 1: Types of Pranayama

\begin{tabular}{|l|l|}
\hline Types of Pranayama & Effect on Body \\
\hline Suryabhedi & A positive effect on the left hemisphere of the brain enhances a person's logical and reasoning ability. \\
\hline Ujjayi & Enhances oxygen consumption. \\
\hline Sitkari & Reduces symptoms of anxiety \\
\hline Sitali & Stress reduction \\
\hline Bhastrika & Revitalizing the lung function \\
\hline Bhramari & Reduces anxiety and other psychological disorders \\
\hline Murcha & Gives mental clarity and induces relaxation and inner awareness. \\
\hline Plavini & Makes a person feel lighter. \\
\hline
\end{tabular}

\section{Indian Nutrition Science and Cognition}

Mental ill-health is essentially a result of a disequilibrium brought about by the unwholesome interaction between the individual and their surrounding environment. This interaction operates through an axis consisting of three fundamental factors, viz. $k \bar{a} l a$ (time rhythm), büddhi (intellect) and indriyātha (sensorial inputs) (13). The great sages Charaka and Sushrut both have elaboratively explained the immense importance of a healthy diet and its relationship with physical and mental well-being. Dincharya and Ritucharya mentioned in Charak Samhita in chapters V and VI respectively of $\mathrm{Su}$ trasthana explain the quantity and quality of diet. This ensures good physical and mental health and longevity. Dincharya gives instructions about how to spend a whole day with mindfulness. Beginning the daily habits with awareness, rising before the sun, cleaning the body, worshipping with gratefulness helps a person to be in the present and thus make him more alert. Also having appropriate food at the appropriate time and eating when one is hungry is a key to health. This makes a perfect balance of body and mind. Sleeping late at night or sleeping in the afternoon disturbs circadian rhythm and thus there occurs an imbalance in the body-mind connection. Following good habits as explained in Ayurvedic literature throughout our life would reduce the chances of mental illness. Ritucharya gives an insight on the consumption of particular food and exercising in a particular manner in specific seasons also balances the body-mind connection. Ayurvedic literature explains the use and properties of several herbs for the treatment of nervous system disorders including memory loss, typically seen in the older population (12). Medicinal plants and herbs such as Ashwagandha, Curcumin, Shankhapushpi, Bramhi to name a few have proven to support mental health. Ashwgandha (Withania somnifera, fam. Solanaceae) is commonly known as Indian Ginseng. Ashwagandha is used as an adaptogen or an anti-stress agent. Constituents of Ashwgandha provide a youthful state of physical and mental health and increase in happiness. Ashwgandha root produces potent antioxidant and antiinflammatory effects against cellular damage by scavenging free radicals. It also protects against inflammatory mediators. (14) Curcumin (Turmeric) reduces oxidative damage and improves cognitive functions related to the ageing process. (15) Bramhi (Bacopa monnieri, fam. Scrophulariaceae) is used in 
many nervous system disorders. It is also used in memory enhancing and for intellect. (16) Also, the holistic approach offered by the teachings of ancient Ayurvedic literature has shown positive effects on improvement in cognition and mental alertness.

\section{Modern Nutrition Science and Cognition}

Mild cognitive impairment refers to the grey zone between the cognitive changes of normal ageing and very early dementia (17). The impact of diet and nutrition on age-related cognition impairment has been extensively studied. It is agreed that various minerals and vitamins which lower the burden of oxidative damage are helpful in the prevention and onset of cognitive decline. (18). Carotenoids, Vitamin C, B6, and folic acid, Vitamin $\mathrm{E}$ have a significant role in managing cognitive impairment. Although supplementation of individual nutrients in preventing dementia has yet to understand fully; certain dietary patterns which include nutrient-rich food have been studied (19). There are ongoing clinical trials on individual nutrients like omega -3 fatty acids, curcuminoids, cocoa and cocoa products, tea and epigallocatachin 3-galate, caffeine, phytoestrogen compounds, resveratrol, Ginko Bioba, garlic and many vitamins investigating their potential effects as neuroprotec- tion. Although there is no substantiated evidence for prescribing these nutrients as supplements. (20) There is always an association between lifestyle and the risk of MCI. The poor nutritional status and cognitive impairments have a strong relation. (21) Across the populations of various ethnicity, culture or religious beliefs, the incidence of chronic diseases including cardiovascular disease and dementia has been studied about dietary patterns. A prolonged or lifelong adherence to the Mediterranean diet is linked with lowered incidences of overall mortality and diseases such as cardiovascular, cancer and has also been effective in incident Parkinson's mortality and AD. (22) As seen in earlier studies; oxidative damage is one of the reasons for cognitive decline and the Mediterranean diet has potential antioxidant properties. (24) Also inflammation is reduced when higher adherence to the Mediterranean diet is followed. (25) A balanced eating plan to stop hypertension known as "Dietary approaches to stop hypertension (DASH diet)" lowers the risk of cardiovascular outcomes. (23). This diet also is a ray of hope in cognitive damage. One largest cohort study indicated that long term adherence to the DASH diet is important to maintain cognitive function in the older population. (26)

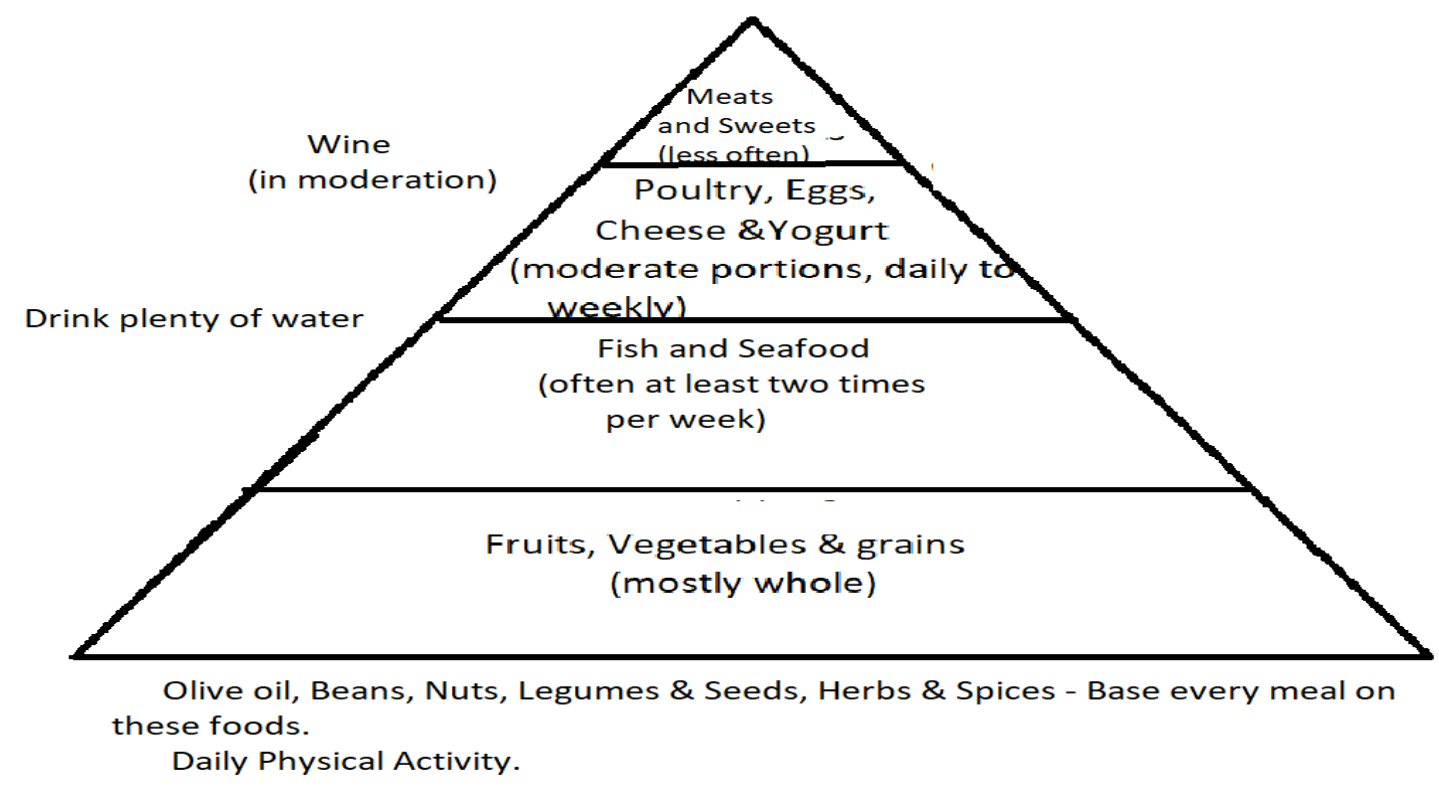

Fig 1: Mediterranean Diet Pyramid 
Results: Lifelong adherence to proper nutrition is associated with better memory. Dietary patterns with the knowledge from the ancient literature of Yoga and Ayurveda are a promising strategy to link between lifestyle and cognitive decline. Therefore, good food with antioxidant/anti-inflammatory properties along with physical activities including concentration techniques is beneficial in maintaining brain function.

\section{CONCLUSION}

This review will certainly be useful to medical practitioners in the holistic management of early diagnosed cognitive decline and all-cause cognitive decline by applying this safe and complementary treatment modality.

\section{REFERENCES}

1. United Nations, Department of Economic and Social Affairs, Population Division (2013) World Population Ageing 2013. ST/ESA/SER.A/348.

2. Petersen R C (2011) Clinical practice. Mild cognitive impairment. N Engl J Med 364, 2227-2234.

3. Petersen RC, Caracciolo B, Brayne C, et al. (2014) Mild cognitive impairment: a concept in evolution. $\mathrm{J}$ $\begin{array}{lll}\text { Intern } & \text { Med } 275(3) \text { : } & \end{array}$ doi:10.1111/joim.12190.

4. Peterson R C (2016) Mild Cognitive Impairment A Review Article. Continuum (Minneap Minn); 22(2):404-418.

5. Murman D.L. (2015) The impact of age on cognition Seminn Hear 2015 Aug; 36(3): 111-121; DOI: 10.1055/s-0035-1555115.

6. T. Shirley, Bhat R.R. Neurophysiological Changes in Meditation Correlated with Descriptions from the Ancient Texts; Biofeedback (2011) 39(2); 56-59; DOI: org/10.5298/1081-5937-39.2.08.

7. Telles $\mathrm{S}$ and Bhat RR Neurophysiological Changes in Meditation Correlated with Descriptions from the Ancient Texts. 2011:56-9.

8. Xiong GL, Doraiswamy PM. Does meditation enhance cognition and brain plasticity? Ann N Y Acad Sci. 2009; 1172:63-9.

9. Guglietti CL, Daskalakis ZJ, Radhu N, Fitzgerald PB, Ritvo P. Meditation-related increases in GABAB modulated cortical inhibition. Brain Stimul.2013; 6:397-402.
10. Lazar SW, Kerr CE, Wasserman RH, Gray JR, Greve $\mathrm{DN}$, Treadway MT, et al. Meditation experience is associated with increased cortical thickness. Neuroreport. 2005; 16:1893-7.

11. Feng Z, Zhang JT. Protective effect of melatonin on beta-amyloid-induced apoptosis in rat astroglioma c6 cells and its mechanism. Free Radic Biol Med. 2004; 37:1790-801.

12. S. Mishra, B. Trikamji, S. Singh, P. Singh, and R. Nair, "Historical perspective of Indian neurology," Annals of Indian Academy of Neurology, vol. 16, no. 4, pp. 467-477, 2013.

13. Charak Samhita; Nidansthana Chapter VII.

14. S. S. Abbas and N. Singh, Anti-stress Agents (Herbs) of Indian Origin - Herbal Drugs, A twenty-firstcentury perspective, D. R. A. D. O. Delhi, Ed., Institute of Nuclear Medicine and Allied, New Delhi, India, 2006.

15. F. Yang, G. P. Lim, A. N. Begum et al., "Curcumin inhibits the formation of amyloid oligomers and fibrils, binds plaques, and reduces amyloid in vivo," The Journal of Biological Chemistry, vol. 280, no. 7, pp. 5892-5901, 2005.

16. S. Roodenrys, D. Booth, S. Bulzomi, A. Phipps, C. Micallef, and J. Smoker, "Chronic effects of Brahmi (Bacopa monnieri) on human memory," Neuropsychopharmacology, vol. 27, no. 2, pp. 279-281, 2002.

17. Geda Y., "Mild Cognitive Impairment in Older Adults", Curr Psychiatry Rep. 2012 Aug; 14(4): 320327. DOI: 10.1007/s11920-012-0291-x.

18. Meydani M. Antioxidants and cognitive function. Nutr Rev. 2001;59: S75- 80. discussion S80-72.

19. Dominguez L., Barbagallo M., "Nutritional prevention of Cognitive Decline and Dementia"; Acta Biomed. 2018; 89(2): 276-290. DOI: 10.23750/abm. v89i2.7401

20. Dominguez L., Barbagallo M., "Nutritional prevention of Cognitive Decline and Dementia"; Acta Biomed. 2018; 89(2): 276-290. DOI: 10.23750/abm. v89i2.7401.

21. Yanhui L., Yu A., Jin G., Xiaona Z., Hui W., Honggao R., Rong X. "Dietary Intake of Nutrients and Lifestyle Affect the Risk of Mild Cognitive Impairment in the Chinese Elderly Population: A CrossSectional Study"; Front. Behav. Neurosci., 29 November 2016 https://doi.org/10.3389/fnbeh.2016.00229.

22. Sofi F., Abbate R., Gensini G., Casini A., "Accuring evidence on benefits of adherence to the Mediterrane- 
an diet on health: an updated systematic review and meta-analysis"; Am J Clin Nutr. 2010 Nov.;92(5):1189-96. Doi: 10.3945/ajcn.2010.29673.Epub 2010 Sep 1.

23. Tyson CC, Nwankwo C, Lin PH, Svetkey LP.; "The Dietary Approaches to Stop Hypertension (DASH) eating pattern in special populations." Curr Hypertens Rep. 2012 Oct; 14(5):388-96.

24. Dai J, Jones DP, Goldberg J, Ziegler TR, Bostick RM, Wilson PW, Ranatunga AK, Shallenberger L, Jones L, Vaccarino V.; Association between adherence to the Mediterranean diet and oxidative stress. Am J Clin Nutr. 2008 Nov; 88(5):1364-70.

25. Giugliano D, Esposito K.; Mediterranean diet and metabolic diseases. Curr Opin Lipidol. 2008 Feb; 19(1):63-8.

26. Berendsen A., Kang J., Rest O., Feskens E., Groot L. The Dietary Approaches to Stop Hypertension Cognitive Function and Cognitive decline in American older women. January 2017. Journal of the American Medical Directors Association 18(5) DOI: 10.1016/j.jamda.2016.11.026.

27. Sharma V., Rajaeyakumar M., Velkumary S., Subramaniam S., Bhavanani A., Madanmohan., Sahai A., Thangavel D. Effect of Fast and Slow Pranayam Practice on Cognitive Functions in Healthy Volunteers. Journal of Clinical and Diagnostic Research.; Published online 2013 Nov 18. DOI: 10.7860/JCDR/2014/7256.3668.

\section{Source of Support: Nil Conflict of Interest: None Declared}

How to cite this URL: Supriya Joshi \& Saloni Jadhav: Yog And Indian Dietetics In Management Of Mild Cognitive Impairment (MCI): A Complimentary Remedial Re-view. International Ayurvedic Medical Journal \{online\} 2021 \{cited December 2021\} Available from: http://www.iamj.in/posts/images/upload/3081_3086.pdf 